\title{
Behavior of Self-Compacting Concrete in Simulated Hot Weather
}

\author{
Mohamed A. Saafan ${ }^{1}$, Zeinab A. Etman ${ }^{1 *}$, and Thamir N. Bait AL-Shab ${ }^{2}$ \\ ${ }^{l}$ Department of Civil Eng, Faculty of Eng., Menoufia University, Egypt \\ ${ }^{*}$ Higher Institute of Eng. and Technology, Menoufia \\ ${ }^{2}$ MSc Candidate, Depart. of Civil Eng., Faculty of Eng., Menoufia University, Egypt
}

\begin{abstract}
Climate changes have been an issue to consider in the last few years. In this research, the performance of selfcompacting concrete in simulated hot weather conditions is investigated. Test parameters included the ambient temperature, induced materials temperature, and the use of a retarder. The rheological properties, early shrinkage, and compressive strength were determined for different test parameters. The performance enhancement due to cooling the concrete materials and the use of a retarder was assessed and quantified. The use of a retarder had an adverse effect on the compressive strength between 7 and 90 days in simulated hot weather conditions. The J-ring test outputs were the most improved due to cooling SCC materials. V-funnel time T5 and the 28-day compressive and tensile strength were the least improved. The use of a retarder further reduced the compressive and tensile strength improvement percentages.
\end{abstract}

Keywords: hot weather; SCC; retarder; shrinkage; mechanical properties.

\section{Introduction}

Cement-based materials are the most widely used among all manufactured materials considering its various applications in the construction industry. Traditional construction and engineering materials are needed to meet new and challenging demands. One of the recent advances in concrete technology was the evolution of Self-Compacted Concrete (SCC) [1]. Self-compacting concrete is a new category of concrete that does not require vibration for placing and compaction. It can flow under its own weight to fill the formwork and achieve full compaction even in the presence of congested reinforcement [2]. Hardened SCC is dense and homogeneous with mechanical and durability properties comparable to that of conventional concrete. Selfcompacting concrete offers higher rates of concrete placement, with faster construction time and ease of flow around congested reinforcement. The fluidity and segregation resistance of SCC ensures a high level of homogeneity, minimal concrete voids, and uniform concrete strength, providing the potential for a superior level of finish and durability to the structure. SCC is often produced with a low water-cement ratio providing the potential for high early strength, high durability, and fast use of elements and structures [3-6].

The consistency of hydraulic cement concrete is significantly influenced the ambient temperature. Special measures during mixing, placing, and curing of concrete should be applied in hot weather. Manufacturing of concrete in hot weather is described in practicing codes and specifications. For this reason, an upper-temperature limit for the acceptance of ready mix concrete is specified. The ACI-305 report states that concrete temperature should not exceed $35^{\circ} \mathrm{C}$ [7], while ASTM -
C94 specifies a limit of $32^{\circ} \mathrm{C}$ [8]. Other standards allow concrete casting only when the temperature is between $29^{\circ} \mathrm{C}$ and $32^{\circ} \mathrm{C}[9]$.

During concrete manufacturing, high ambient temperature induces problems that refer to increased cement hydration and mixing water evaporation rates. The rate of cement hydration is dependent on its temperature, cement composition, and its fineness, and the use of admixtures [7]. Increased cement hydration and water evaporation rates not only impede the fresh concrete state, but also affect the strength and durability of hardened concrete. The research work conducted by Park et.al [10] showed that water contents, hydration products, and the pore structure are the main factors affecting strength. Their work was carried out under typical summer weather conditions. The results showed that the elevated summer temperature did not influence the early age concrete strength. On the other hand, significant loss of strength was recorded at later ages due to the restriction of hydration products development and increased porosity [11].

Fresh concrete properties are influenced by high ambient temperature and exposure to direct solar radiation and concerting circumstances get worse with speedy wind $[12,13]$. Plastic shrinkage occurs before concrete setting due to water evaporation from the concrete surface [14]. Plastic shrinkage, cracking, and strength reductions occur due to the exposure to the aforementioned factors $[15,16]$. Kar and Sanjay reported the benefits of using different admixtures to control SCC shrinkage [17]. Kamal et al. studied the retempering of SCC concrete to maintain the flow characteristics [18]. Over the past 50 years, the average global temperature has increased at 
the fastest rate in recorded history and this trend is accelerating $[19,20]$. These statistics motivated the current work to explore SCC production in hot weather.

\section{Aim and Research Significance}

The significance of the current work arises from the fact that SCC basic requirement is related to its consistency and its ability to flow during placement. Thus, ambient temperature considerations are more critical for SCC compared to conventional concrete. The research concerns are gaining interest taking into account the worldwide climate changes. For many reasons, the temperature limits through the year, and the difference between night and day have considerably changed. The aim of this research was to study the influence of increasing ambient temperature and the temperature of concrete materials including water, cement and aggregates on both SCC fresh and hardened properties.

\section{Experimental Program}

The current work aimed to evaluate the influence of high ambient temperature on SCC strength, flow indicators, and early shrinkage of SCC mixes. The evaluation was based on the test results of similar control mixes cast at room temperature. The materials were heated to simulate their condition in concrete manufacturing plants. Two concrete mixes, with and without the addition of a chemical retarder, were proportioned for testing. Table (1) shows the concrete mix proportions.

TABLE 1- SCC Mix Constituents $\left(\mathrm{kg} / \mathrm{m}^{3}\right)$

\begin{tabular}{lcc}
\hline SCC Constituents & Mix\#1 & Mix\#2 \\
\hline Portland cement & 450 & 450 \\
Free water & 150 & 150 \\
Fine aggregate & 990 & 990 \\
Coarse aggregate & 850 & 850 \\
Superplasticizer & 9.0 & 7.5 \\
Retarder & 0.0 & 2.0 \\
\hline
\end{tabular}

A thermally insulated chamber was specially constructed with internal ambient temperature control. All concrete mixing, casting, and curing procedures were conducted inside the chamber. The chamber was $4.0 \mathrm{~m}$ long, $2.5 \mathrm{~m}$ wide, and $2.2 \mathrm{~m}$ high with wooden walls and ceiling covered with reflective aluminum-coated air bubble thermal insulation sheets as shown in Figure (1). Electric rotating heaters and a fan were used to evenly heat the chamber working area. The temperature inside the chamber was monitored and controlled from the outside to avoid opening the chamber frequently. The relative humidity inside the chamber was $46 \pm 3$. The solid materials were heated to the specified temperature of $50^{\circ} \mathrm{C}$ in a 2000 liter electric oven.

Table (2) shows the test parameters in terms of the temperature inside the chamber $\left(50^{\circ} \mathrm{C}\right)$ and the temperature of SSC materials (mixing water $35^{\circ} \mathrm{C}$ and solid materials $50^{\circ} \mathrm{C}$ ) versus a control temperature of $25^{\circ} \mathrm{C}$. A test code in Table (2) indicates the parameter (room, mixing water, solid materials) or combined parameters with increased temperature above the control temperature of $25^{\circ} \mathrm{C}$. For example, test code (W) indicates increased temperature of mixing water, while WMR indicates increased mixing water, solid materials, and room (ambient) temperatures.

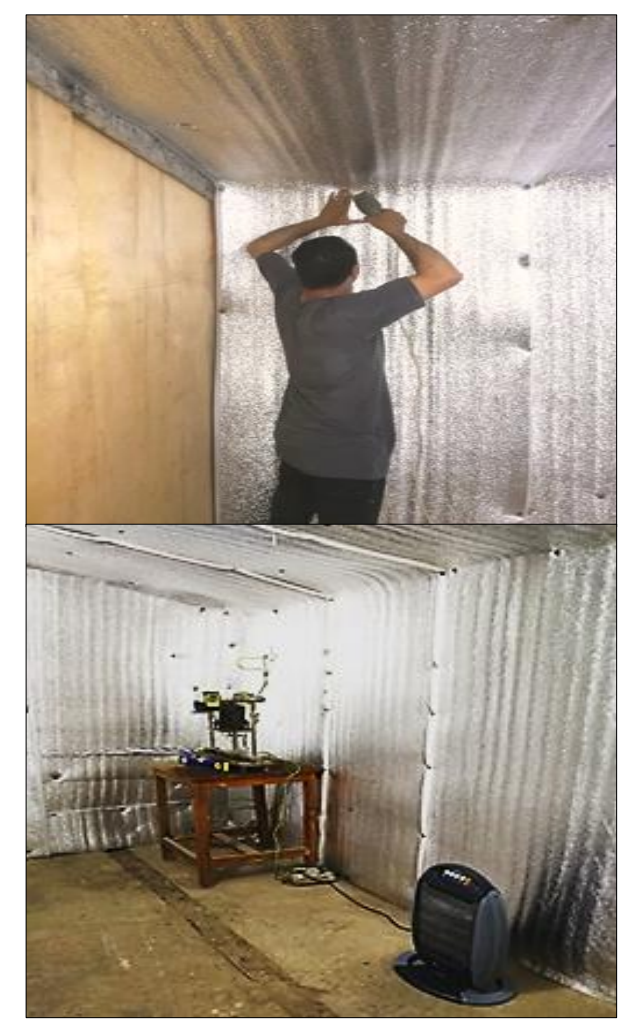

Fig.1- Temperature-controlled chamber

TABLE 2- Test Codes and the Corresponding Temperatures

\begin{tabular}{lccc}
\hline \multirow{2}{*}{ Test code } & \multicolumn{3}{c}{ Temperature, ${ }^{\circ} \mathrm{C}$} \\
\cline { 2 - 4 } & Water & Materials & Room \\
\hline $\mathrm{C}$ & 25 & 25 & 25 \\
$\mathrm{~W}$ & 35 & 50 & 25 \\
\hline $\mathrm{M}$ & & 25 & 50 \\
$\mathrm{R}$ & 25 & 50 & 50 \\
$\mathrm{MR}$ & & 50 & 25 \\
$\mathrm{WM}$ & & 25 & 50 \\
WR & 35 & 50 & 50 \\
WMR & & & \\
\hline
\end{tabular}

The tests on fresh SCC mixes included the slump flow, Jring, and V-funnel. The tests were carried out according to the requirements and standard procedures of the European Federation (EFNARC) SCC guidelines [21]. The slump flow tests were also performed after 20-min. of mixing to evaluate the effect of delayed casting. Then, concrete was retempered by the addition of a limited dose of the retarder $\left(1.0-\mathrm{kg} / \mathrm{m}^{3}\right)$, remixed, and retested. Shrinkage testing was carried out according to ASTM C827M [22]. The tests on hardened concrete included determining compression, splitting tensile, and flexure strength at different ages between 7 and 90 days. 


\subsection{Materials}

The cement used was Portland cement CEMI-42.5N. Fine aggregate was natural siliceous sand with a specific gravity of 2.65 and a fineness modulus of 2.3. Crushed dolomite size $4.75-12.5 \mathrm{~mm}$ was used as coarse aggregate (well-graded according to ASTM C-33 [23], a specific gravity of 2.60, and crushing modulus of 19.5). A superplasticizer meeting the requirements of ASTM C-494 types G\&F [24] and a retarder meeting the requirements of ASTM C-494 types G were used. The superplasticizer is Poly-Carboxylate Ether based $3^{\text {rd }}$ generation chemical admixture. This category of admixtures has a long-chain molecular structure that helps produce highly fluid yet a stable concrete while acting as a viscosity-modifying agent.

\subsection{Test specimens}

The compressive strength test specimens were 100-mm cubes. $100 \times 200-\mathrm{mm}$ cylinders were used to determine the splitting tensile strength $\left(f_{s p}\right)$ and shrinkage and $100 \times 100 \times 500-\mathrm{mm}$ prisms to determine the flexure strength $\left(f_{r}\right)$.

\section{Test Results and Discussion \\ 4.1 SCC Rheological Properties}

The performance of fresh SCC mixes in terms of standard test results (Slump flow, J-ring, and V-funnel tests) are reported in Table (3) for mixes 1 and 2. The slump flow test is used to assess SCC horizontal free flow in the absence of obstructions. The influence of a test element temperature (room $\mathrm{R}$, mixing water $\mathrm{W}$, and solid materials $M$ ) on the slump flow diameter is shown in Figure (2). It can be seen that an average slump flow diameter reduction of 5 percent was recorded for one test parameter ( $\mathrm{W}, \mathrm{M}$, and $\mathrm{R})$. As the test parameters were combined into two and three parameters, the percentage reduction further increased to 9 and 15 percent, respectively.
The T50 time is a secondary indication of flow ability. Figure (3) shows the measured T50 time for different test codes. The flow time increased by 28,62 , and 75 percent as the temperature of one, two, and three test parameters was increased, respectively. The results indicate that the flow and filling ability was restricted as the temperatures increased.

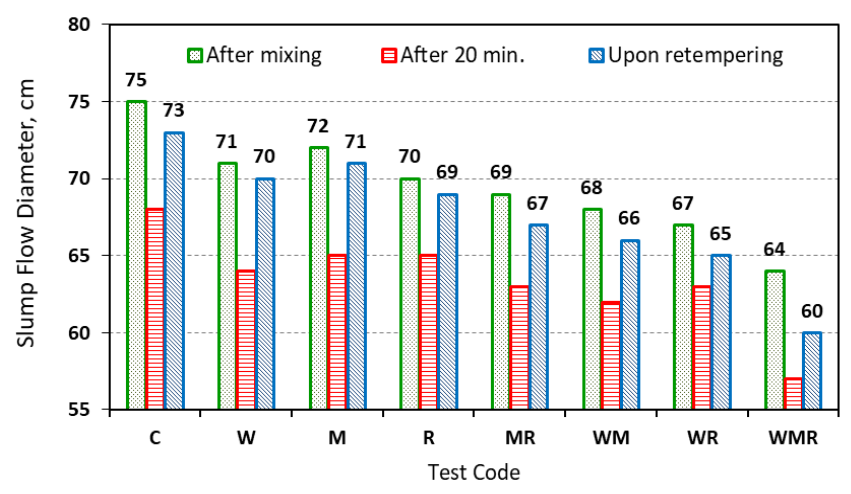

Fig. 2- Slump Flow Diameter for for Different Test Codes (Mix \#1)

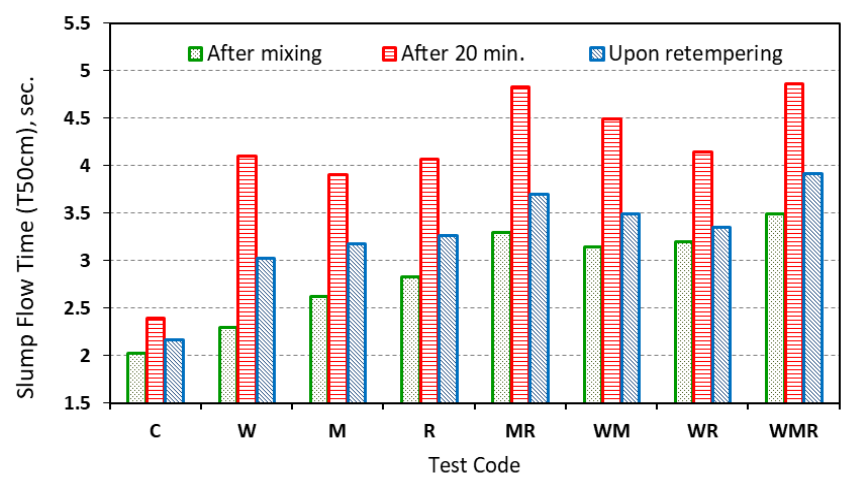

Fig. 3- Slump Flow Time for Different Test Codes (Mix \#1)

TABLE 3- SCC Flow \& Passing Ability Indicators and Shrinkage for Different Test Codes

\begin{tabular}{|c|c|c|c|c|c|c|c|c|c|c|c|c|}
\hline \multirow{3}{*}{$\begin{array}{l}\text { SCC } \\
\text { Mix }\end{array}$} & \multirow{3}{*}{$\begin{array}{l}\text { Test } \\
\text { Code }\end{array}$} & \multicolumn{6}{|c|}{ Slump flow * } & \multicolumn{2}{|c|}{$J$-ring } & \multicolumn{2}{|c|}{$V$-funnel } & \multirow{3}{*}{$\begin{array}{l}\text { 24-h Height } \\
\text { change } \\
\left(\times 10^{-3}\right)\end{array}$} \\
\hline & & \multicolumn{2}{|c|}{ (1) } & \multicolumn{2}{|c|}{$(2)$} & \multicolumn{2}{|c|}{ (3) } & \multirow{2}{*}{$\begin{array}{c}\mathrm{D} \\
(\mathrm{cm})\end{array}$} & \multirow{2}{*}{$\begin{array}{c}\mathrm{H} 1-\mathrm{H} 2 \\
(\mathrm{~mm})\end{array}$} & \multirow{2}{*}{$\begin{array}{c}\mathrm{T} \\
(\mathrm{sec})\end{array}$} & \multirow{2}{*}{$\begin{array}{c}\mathrm{T} 5 \\
(\mathrm{sec})\end{array}$} & \\
\hline & & $\begin{array}{c}\mathrm{D} \\
(\mathrm{cm})\end{array}$ & $\begin{array}{c}\text { T50 } \\
(\mathrm{sec})\end{array}$ & $\begin{array}{c}\mathrm{D} \\
(\mathrm{cm})\end{array}$ & $\begin{array}{c}\text { T50 } \\
(\mathrm{sec})\end{array}$ & $\begin{array}{c}\mathrm{D} \\
(\mathrm{cm})\end{array}$ & $\begin{array}{c}\text { T50 } \\
(\mathrm{sec})\end{array}$ & & & & & \\
\hline \multirow{8}{*}{$\# 1$} & $\mathrm{C}$ & 75 & 2.03 & 68 & 2.40 & 73 & 2.17 & 71 & 10 & 10.08 & 12.40 & 2.90 \\
\hline & $\mathrm{W}$ & 71 & 2.30 & 64 & 4.10 & 70 & 3.03 & 67 & 12 & 14.01 & 18.00 & 3.53 \\
\hline & $\mathrm{M}$ & 72 & 2.63 & 65 & 3.91 & 71 & 3.18 & 65 & 15 & 13.43 & 16.08 & 3.46 \\
\hline & $\mathrm{R}$ & 70 & 2.83 & 65 & 4.07 & 69 & 3.27 & 66 & 14 & 14.09 & 18.45 & 4.37 \\
\hline & MR & 69 & 3.30 & 63 & 4.83 & 67 & 3.70 & 63 & 17 & 15.70 & 22.15 & 4.46 \\
\hline & WM & 68 & 3.15 & 62 & 4.50 & 66 & 3.50 & 60 & 19 & 15.32 & 21.17 & 4.55 \\
\hline & WR & 67 & 3.20 & 63 & 4.15 & 65 & 3.35 & 62 & 18 & 16.17 & 20.32 & 4.59 \\
\hline & WMR & 64 & 3.50 & 57 & 4.86 & 60 & 3.92 & 58 & 22 & 17.10 & 22.04 & 5.61 \\
\hline \multirow{3}{*}{$\# 2$} & $\mathrm{C}$ & 72 & 2.17 & 71 & 2.30 & $\overline{--}$ & -- & 70 & 12 & 10.20 & 11.20 & 3.25 \\
\hline & $\mathrm{R}$ & 67 & 2.90 & 65 & 3.10 & -- & -- & 64 & 15 & 14.40 & 17.20 & 4.76 \\
\hline & WMR & 61 & 3.55 & 59 & 3.70 & -- & -- & 55 & 19 & 18.00 & 21.80 & 6.10 \\
\hline
\end{tabular}

*(1) immediately after mixing, (2) after 20 min. of mixing, (3) mix retempered after 20 min. 
Figure (2) shows the slump flow diameter after 20 minutes during which the concrete was left to settle after mixing. The flow diameter decreased by about 9 percent in the control condition $\mathrm{C}$. This ratio increased on average to about 14,16 , and 24 percent for one, two, and three test parameters, respectively considering the control flow diameter as a reference. However, the reduction ratio due to only the time was independent of the test parameter as the flow diameter decreased by an average of 9 percent for all test codes. Similar results were obtained for T50 as shown in Figure (3). T50 increased by about 18 percent in the control condition $\mathrm{C}$. This ratio increased on average to 98, 121 and 139 percent for one, two, and three test parameters, respectively considering the control flow diameter as a reference. Also, the percentage increase was 43 on average for all test codes due to only the time.

Once retempered, mix\#1 slump flow test was performed. The results in Table (3) show that 97 percent of the flow diameter was retrieved in the control condition $\mathrm{C}$. This ratio decreased on average to 93,88 , and 80 percent for one, two, and three test parameters, respectively considering the control flow diameter as a reference. In all test codes, no less than 94 percent of the corresponding initial flow diameter was retrieved. On the other hand, T50 increased by about 7 percent in the control condition $\mathrm{C}$. This ratio increased on average to 56, 73, and 93 percent for one, two, and three test parameters, respectively considering the control flow diameter as a reference.

These above results indicate that the flow rate was more adversely affected by increased temperature and delayed casting compared to the slump flow diameter. In the same context, the initial flow diameter was satisfactorily restored by retempering concrete, while the flow rate in terms of T50 was not adequately restored.

The J-Ring test determines the passing ability of SCC by measuring the flow diameter (indicating the restricted flow due to blocking of reinforcement bars), flow time (indicating the rate of flow), and blocking step (H1-H2) that quantifies the effect of blocking. Figure (4) shows an average flow diameter reduction of 6.7 percent due to the temperature increase of a single parameter. The corresponding ratios for two and three parameters were 13.0 and 18.3 percent, respectively. The effect of increased temperature on the robustness of SCC is also illustrated in Figure (5) showing the same pattern for increased blocking step.

The V-funnel test mainly measures the filling ability and viscosity of SCC in terms of the time (T) taken for SCC to flow through the apparatus. The funnel is refilled and concrete is left for 5 minutes to settle. If concrete shows segregation, then the flow time (T5) will increase significantly. Figure (6) shows the measured V-funnel T time for different test codes. The flow time increased by an average of 37,56 , and 69 percent as the temperature of one, two, and three test parameters was increased, respectively. The corresponding $\mathrm{T} 5$ ratios were 41,71 , and 77 percent.

Mix \#2 with a retarder addition was tested for codes C, $\mathrm{R}$, and WMR. The results in Table (3) show that the slump flow diameter values were slightly less and the T50 values were higher than the corresponding values of mix \#1. This was attributed to the less content of the more efficient superplasticizer in mix\#2. The benefit of using a retarder was observed after 20-min. as the change in both the flow diameter and T50 was limited and there was no need for retempering.

Table (4) shows the limits of the rheological properties for satisfactory performance and economic mix design according to EFNARC [21]. The results reported in Table (3) show that the designed control mixes fulfilled all specified limits. In the WMR test, the J-ring flow diameter and the slump flow diameter after 20-min. were under the lower limit by about $100 \mathrm{~mm}$ which can still be acceptable. Exceptionally higher than the upper limit were the blocking step and V-funnel times $\mathrm{T}$ and $\mathrm{T} 5$ in WMR. The results indicate that cooling the concrete constituents is sufficient to retrieve these properties to the desired limits.

TABLE 4- Typical Fresh SCC Limits [21]

\begin{tabular}{lcc}
\hline \multirow{2}{*}{ Method } & \multicolumn{2}{c}{ Limits } \\
\cline { 2 - 3 } & min. & $\max$. \\
\hline Slump flow diameter ,mm & 650 & 800 \\
Slump flow T50, sec. & 2 & 5 \\
J-ring blocking step, mm & 0 & 10 \\
V-funnel time T, sec. & 6 & 12 \\
V-funnel time T5, sec. & 6 & 15 \\
\hline
\end{tabular}


Mohamed A. Saafan, Zeinab A. Etman, and Thamer N. Bait AL-Shab "Behavior of Self-Compacting con..."
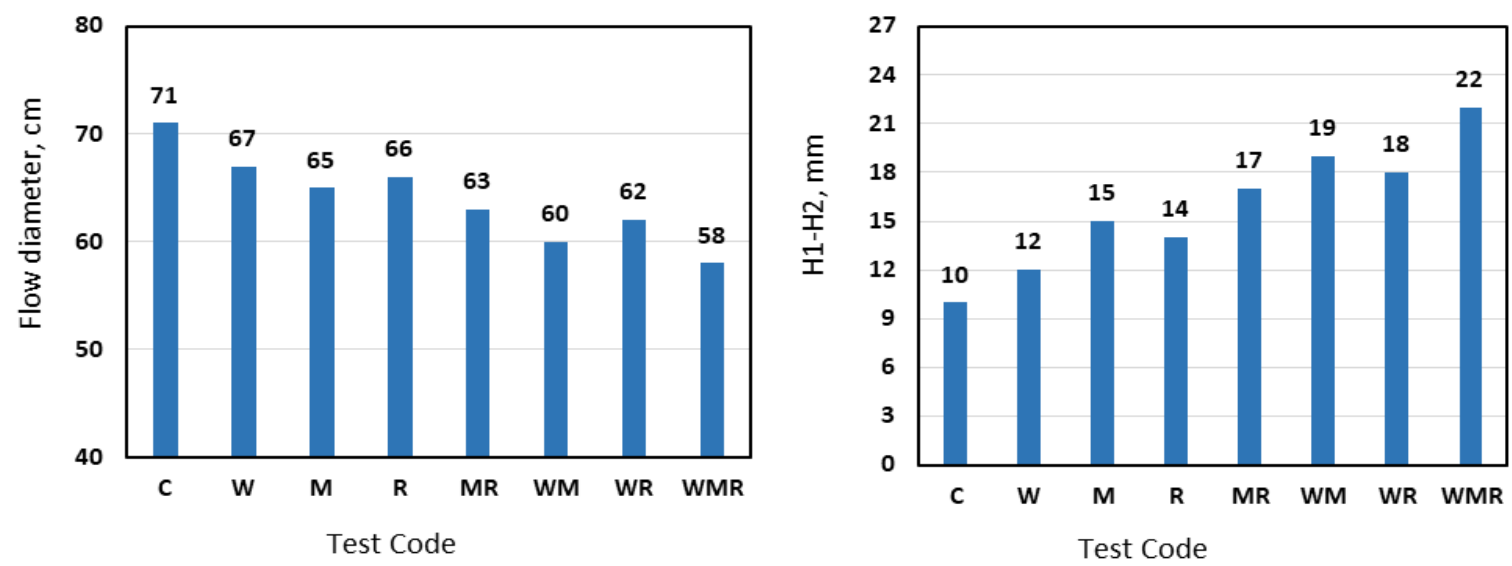

Fig. 4- J-Ring Flow Diameter and Blocking Step for Different test Codes (Mix \#1)
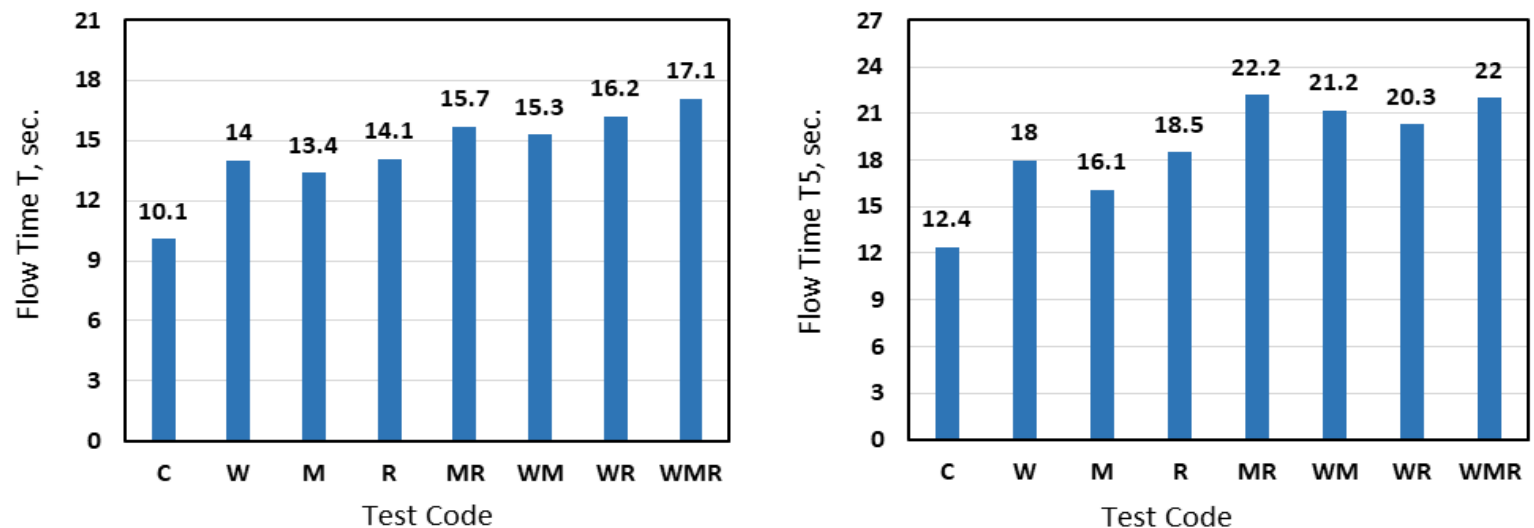

Fig. 5- V-Funnel Time (T \& T5min.) for Different Test Codes (Mix \#1)

\subsection{Early Shrinkage}

Volume changes in SCC mixes were measured during 24 hours after casting the molds by measuring the change in height according to ASTM C-827 [22]. Height change of a laterally confined specimen mainly includes shrinkage due to settlement, hydration, and evaporation. Figure (6) shows the height change measurements for mix \#1. Initially, height changes linearly at a highe rate due to gravitational settlement and water evaporation. Nonlinear deformations were recorded after 30-min. in all test codes. This was attributed to the contribution of autogenous shrinkage, as the volume occupied by the cement hydration products is less than the volume of the reacting ingredients. Volume change continued due to autogenous and drying shrinkage at a relatively low rate (test codes $\mathrm{C}$ ) and relatively higher rates in the case of $\mathrm{R}$, MR, WR, and WMR test codes due to the induced temperature effects and increased drying rates. The results in Table (3) show that the shrinkage after 24hours was 1.5 and 1.9 times the control in test codes test code $\mathrm{R}$ and WMR, which is quite significant. Using a retarder in mix \#2 (test codes $\mathrm{C}, \mathrm{R}$, and WMR) did not alter the shrinkage performance illustrated in Figure (6).
However, the measured 24-hour shrinkage values were $1.1,1.6$, and 2.1 times that of the control $\mathrm{C}$ in mix \#1. Increased shrinkage was attributed to delayed setting allowing more plastic shrinkage before concrete setting.

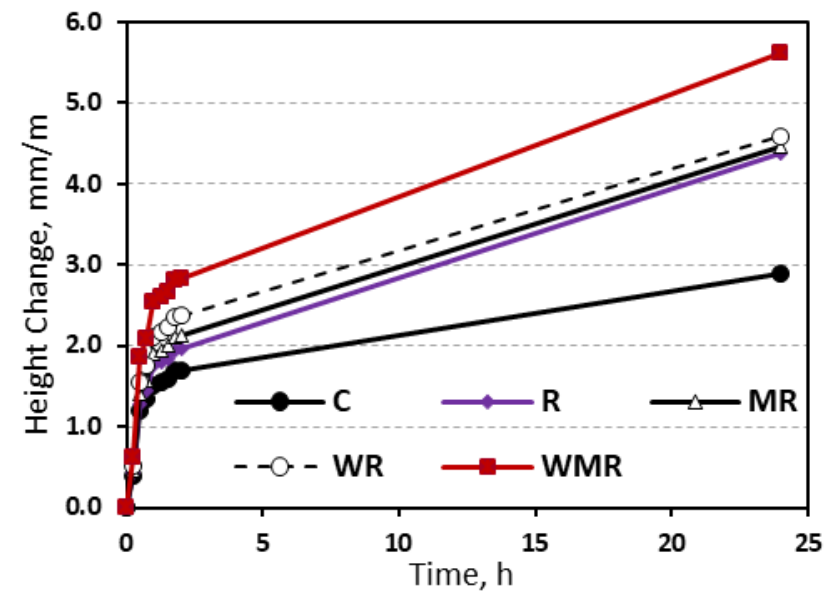

Fig. 6- Shrinkage Measurements for different test codes (mix \#1) 


\subsection{Hardened Concrete Properties}

SCC mixes prepared in high ambient temperatures (test codes R, M R, WR, and WMR) were cured in the conditioning chamber for seven days under a continuously wet cloth while the temperature was raised to $50 \mathrm{oC}$ for 6 -hours/day. Then, the specimens were kept in the laboratory atmosphere $(25 \mathrm{oC}$, relative humidity $50 \pm 4$ until testing). Table (5) shows the test results of the compressive strength at different ages and the tensile strength.

Figure (7) shows the development of compressive strength up to 90-day age for mix \#1. The compressive strength continued to decrease as the number of test parameters increased. The compressive strength in WMR decreased by 34,26 , and 14 percent of the control value at 7,28 , and 90 days, respectively. Strength reduction was attributed to hindered cement hydration due to lack of water. Increased temperature resulted in high evaporation rates in the SCC mix initially proportioned with a low water/cement ratio.

Figure (8) shows the development of compressive strength up to 90-day age for mix \#2. The use of a retarder in mix\#2 decreased the control compressive strength compared to that of mix \#1 by no more than 3.0 percent. This ratio was much higher in mix WMR that showed an average strength reduction of 40 percent independent of the age. This indicated that the use of retarder to maintain the rheological SCC properties had an adverse effect on the compressive strength at elevated temperatures between 7 and 90 days. Similar results apply for the tensile strength in terms of the splitting tensile and fracture strength.

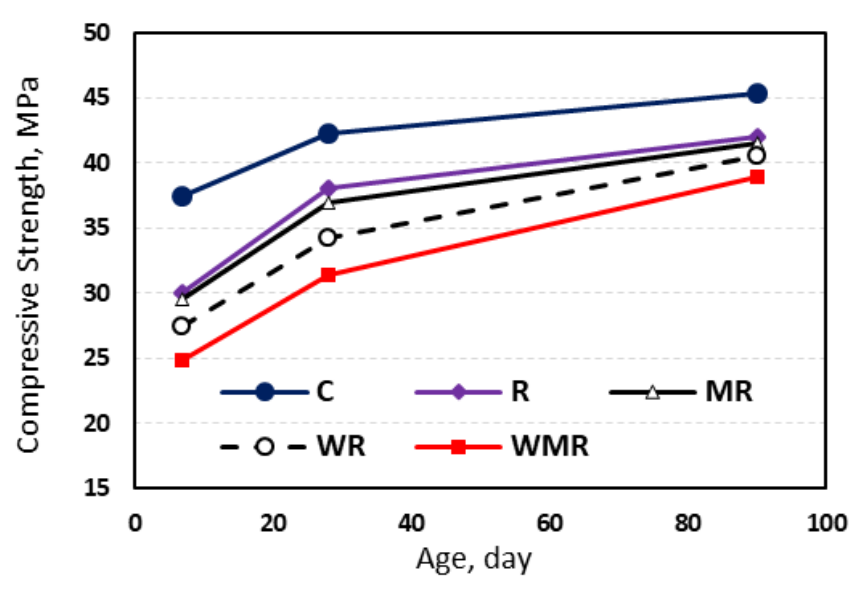

Fig.-7 Compressive Strength Development (mix 1)

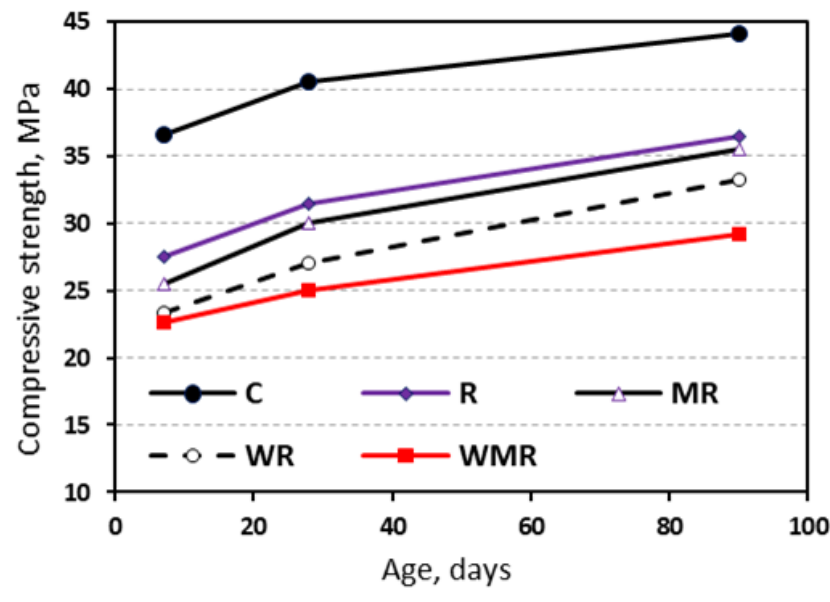

Fig. 8- Compressive Strength Development (mix 2)

TABLE 5- SCC Strength (MPa) at Different Ages (Days)

\begin{tabular}{|c|c|c|c|c|c|c|}
\hline \multirow{2}{*}{$\begin{array}{l}\text { SCC } \\
\text { Mix }\end{array}$} & \multirow{2}{*}{ Test Code } & \multicolumn{3}{|c|}{$f_{c u}$} & \multirow{2}{*}{\multicolumn{2}{|c|}{$\begin{array}{c}f_{s p} f_{r} \\
\text { 28-day }\end{array}$}} \\
\hline & & 7-day & 28-day & 90-day & & \\
\hline \multirow{5}{*}{$\# 1$} & $\bar{C}$ & 37.5 & 41.2 & 45.3 & 3.0 & 4.1 \\
\hline & $\mathrm{R}$ & 30.1 & 38.0 & 42.0 & 2.8 & 3.9 \\
\hline & MR & 29.5 & 36.9 & 41.5 & 2.8 & 4.0 \\
\hline & WR & 27.5 & 34.2 & 40.5 & 2.7 & 3.9 \\
\hline & WMR & 24.9 & 31.4 & 38.9 & 2.7 & 3.8 \\
\hline \multirow{5}{*}{$\# 2$} & $\mathrm{C}$ & 36.6 & 40.5 & 44.1 & 3.1 & 3.9 \\
\hline & $\mathrm{R}$ & 27.5 & 31.5 & 36.5 & 2.6 & 3.5 \\
\hline & MR & 25.5 & 30.0 & 35.5 & 2.5 & 3.5 \\
\hline & WR & 23.2 & 24.5 & 33.3 & 2.4 & 3.2 \\
\hline & WMR & 22.6 & 25.0 & 29.2 & 2.2 & 3.0 \\
\hline
\end{tabular}

$f_{c u}$ : Compressive strength, $f_{s p}$ : Splitting tensile strength, $f_{r}:$ Rupture modulus

A common practice of concrete manufacturing in hot weather is cooling the concrete constituents before mixing. The reported results were used to quantify the benefit of cooling the constituents (mixing water $\mathrm{W}$ and solid materials $\mathrm{M}$ ) for a given SCC performance indicator based on the indicator value in $\mathrm{C}$, ambient temperature $\mathrm{R}$, and the combined WMR test codes.
The percentage enhancement gained for indicator $i$ is defined according to the following equation:

Enhancement, $\%=\left|\left(i_{\mathrm{R}}-i_{\mathrm{WMR}}\right) /\left(i_{\mathrm{c}}-i_{\mathrm{WMR}}\right)\right| \mathrm{x} 100$

Table (6) shows the percentage enhancement for the examined SCC performance indicators when concrete is being manufactured in hot weather conditions as simulated in the current work. 
TABLE 6- SCC Indicator Enhancement Due to The Cooling of Concrete Materials

\begin{tabular}{lcc}
\hline \multirow{2}{*}{ Indicator $i$} & \multicolumn{2}{c}{ Enhancement, \% } \\
\cline { 2 - 3 } & $\operatorname{mix} \# 1$ & $\operatorname{mix} \# 2$ \\
\hline Slump flow diameter & 54.5 & 54.4 \\
Slump flow time, T50 & 46.7 & 47.1 \\
\hline J-Ring flow diameter & 61.5 & 60.0 \\
J-Ring blocking step & 66.7 & 62.5 \\
\hline V-Funnel flow time, T & 42.9 & 46.3 \\
V-Funnel flow time, T5 & 36.5 & 43.4 \\
\hline Shrinkage (height change) & 45.8 & 50.2 \\
\hline 28-day comp. strength & 41.3 & 35.0 \\
Splitting tensile strength & 33.3 & 23.5 \\
\hline
\end{tabular}

Among the properties listed in Table (6), the J-ring outputs were the most improved due to cooling SCC materials. On the other hand, V-funnel time T5, 28-day compressive strength, and tensile strength were the least improved. Compared to mix \#1, the use of a retarder in mix \#2 reduced the compressive and tensile strength improvement percentage, while the enhancement percentage of V-funnel T5 time was higher.

\section{Conclusions}

In the current work, two SCC mixes were tested to study the rheological and hardened properties under circumstances simulating concrete manufacturing in hot weather. The ambient temperature and induced concrete materials temperature and their combinations were test parameters. The performance enhancement due to the cooling of concrete materials to $25^{\circ} \mathrm{C}$ and the use of a retarder in one mix were assessed and quantified. Based on the experimental test results in simulated hot weather conditions, the following conclusions were drawn:

1. The flow and filling ability was restricted as the temperatures increased. The flow rate was more adversely influenced by increased temperature and delayed casting compared to the slump flow diameter. In the same context, the initial flow diameter rather than the flow rate was satisfactorily restored by retempering after 20 minutes of mixing.

2. The J-ring flow diameter and the slump flow diameter after 20-min. were below typical limits specified for satisfactory SCC performance. On the other hand, the blocking step and V-funnel times ( $\mathrm{T}$ and T5) were exceptionally higher than the upper limit. Cooling the concrete constituents was sufficient to retrieve these properties to the desired limits.

3. While, the use of a retarder maintained the slump flow performance, increased shrinkage in terms of height change was considerably increased due to delayed setting allowing more plastic shrinkage before concrete setting.

4. The use of a retarder had an adverse effect on the compressive strength between 7 and 90 days in simulated hot weather conditions.
5. The J-ring outputs were the most improved due to cooling SCC materials. On the other hand, V-funnel time T5 and the 28-day compressive and tensile strength were the least improved. The use of a retarder further reduced the compressive and tensile strength improvement percentage and increased the percentage enhancement of V-funnel T5 time.

\section{References}

[1] A. Yahai, M. Tanimura, A. Shimabukuro, and Y. Shimayama, "Effects of rheological parameters on self-compact ability of concrete containing various mineral admixtures" First International RILEM Symposium, Stockholm, Sweden, September 1999, pp. 13-14.

[2] B.V. Chavan, and P.O. Modani. "Experimental investigation on self-compacting concrete by replacing natural sand with artificial sand" International Research Journal of Engineering and Technology (IRJET), Vol. 6, No. 5, May 2019, pp. 6901-6903.

[3] D.E. Branson and M.L. Christiason, "Timedependent concrete properties related to designstrength and elastic properties" Designing for Effects of Creep, Shrinkage, Temperature in Concrete Structures, SP-27, American Concrete Institute, Detroit, pp. 257-277.

[4] S.R. Ramesh, H. Venugopal, and N. Jayaramappa, "Literature review on self-compacting concrete" Paripex-Indian Journal of Research, Vol. 8, No. 2, pp. 20-22, https://www.doi.org/10.36106/paripex

[5] M. Hayakawa, et.al, "Development and application of super workable concrete" In Special Concretes: Workability and Mixing; E\&FN Spon, London, 1994, pp. 183-190.

[6] Y.F, Silva, R.A. Robayo, P.E. Mattey, and S. Delvasto, "Properties of self-compacting concrete on fresh and hardened with residue of masonry and recycled concrete" Construction and Building Materials, Vol. 124, pp. 639-644. DOI: 10.1016/j.conbuildmat.2016.07.057

[7] ACI 305R-10, "Guide to hot weather concreting" ACI Committee 305, 20p.

[8] ASTM C-94, "Ready-mixed concrete" ASTM Committee C09, Feb. 2000, 10 p.

[9] M. Nasir, O.S.B Al-Amoudi, H.J. Al-Gahtani, and M. Maslehuddin, "Effect of casting temperature on strength and density of plain and blended cement concretes prepared and cured under hot weather conditions" Construction and Building Materials, Vol. 112, 2016, pp. 529-537.

DOI: 10.1016/j.conbuildmat.2016.02.211 
[10] K.B. Park, and T. Noguchi, "Effects of mixing and curing temperature on the strength development and pore structure of fly ash blended mass concrete" Advances in Materials Science and Engineering, 2017, 11p.

DOI: $10.1155 / 2017 / 3452493$

[11] J. Ortiz, A. Aguado, L. Agulló, and T. Garca, "Influence of environmental temperatures on the concrete compressive strength: Simulation of hot and cold weather conditions" Cement and concrete research, Vol. 35, No. 10, 2010, pp. 1970-1979. http://hdl.handle.net/2117/2484

[12] O.S.B. Al-Amoudi, M. Maslehuddin, M. Shameem, I. Mohamed, "Shrinkage of plain and silica fume cement concrete under hot weather" Cement and Concrete Composites, 2016, Vol. 29, No. 9, pp. 690-699.

DOI: 10.1016/j.cemconcomp.2007.05.006

[13] R. Shalon, "Report on behavior of concrete in hot climate" Part I. Materials and Structures, Vol. 11, No. 62, 1987, pp. 127-131.

[14] ACI Committee 116, "Cement and Concrete Terminology" ACI Manual of Concrete Practice, American Concrete Institute: Farmington Hills, 2000 .

[15] B.H. Ahmadi, "Initial and final setting time of concrete in hot weather" Materials and Structures, Vol. 33, 2000, pp. 511-514.

https://doi.org/10.1007/BF02480528

[16] C. Ishee, and S. Surana, "Hot weather concreting" In Developments in the Formulation and Reinforcement of Concrete." Wood Head Publishing, 2019, pp. 131-150.
[17] S. Kar and S. Sanjay "Effect of admixtures on shrinkage properties in self-compacting concrete" International Journal of Research in Engineering and Technology, 2016, Vol. 5, No. 2, pp. 292-296.

[18] Kamal, M.M., Safan, M.A., Etman, Z.A., and ELdabouly, E. A., "Evaluating the Prolonged Properties of Fresh Self-compacting Concrete Incorporating Recycled Aggregates" International Journal of Current Engineering and Research, Vol. 3, No. 2, June 2013, pp. 436-446.

[19] S. Al-Martini and M. Al-Khatib, "Rheology of selfconsolidating concrete (SCC) under hot weather conditions" Construction Materials, October 2017, 12p. DOI: $10.1680 /$ jcoma.17.00017

[20] T.R. Karl, et.al, "Possible artifacts of data biases in the recent global surface warming hiatus" Science, Vol. 348, No. 6242, January 2015, pp. 1469-1472. DOI: $10.1126 /$ science.aaa5632

[21] European Federation of National Associations Representing for Concrete (EFNARC), "Specifications and guidelines for self-compacting concrete" 2002, 32p.

[22] ASTM C827/C827M - 10 "Change in Height at Early Ages of Cylindrical Specimens of Cementitious Mixtures" 2010, 5p.

[23] ASTM Standard C33, 2003 (2006), "Specification for Concrete Aggregates" ASTM International, West Conshohocken, PA, 2006, DOI:10.1520/C0033-03R06

[24] ASTM C-494 "Chemical Admixtures for Concrete" ASTM Committee C09, 1999, 9p. 